\title{
Erratum to: Efficacy and Safety of Propofol-Mediated Sedation for Outpatient Endoscopic Retrograde Cholangiopancreatography (ERCP)
}

\author{
Priya Farooq $^{1} \cdot$ Kate Zwilling $^{1} \cdot$ Devi Patel $^{1} \cdot$ Ali A. Siddiqui ${ }^{1}$
}

Published online: 13 May 2016

(C) Springer Science+Business Media New York 2016

\section{Erratum to: Dig Dis Sci}

DOI 10.1007/s10620-016-4043-3

In the original version of the article Juliana F. Yang was listed as the first author of the article. Unfortunately, JF Yang did not fulfill the criteria for authorship for the article. This erratum is issued to remove the author from the author group.

The authors wish to thank JF Yang for assistance with the editing of the article.

The online version of the original article can be found under doi:10.1007/s10620-016-4043-3.

$\triangle$ Ali A. Siddiqui

Ali.Siddiqui@Jefferson.edu

1 Division of Gastroenterology and Hepatology, Department of Internal Medicine, Thomas Jefferson University Hospital, Philadelphia, PA 19107, USA 